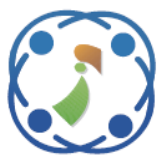

\title{
Optimal Load Control for Economic Energy Equilibrium in Smart Grid Using Adaptive Inertia Weight Teaching-Learning-Based Optimization
}

\author{
Nirmala John ${ }^{1 *}$ \\ Varaprasad Janamala ${ }^{1}$ \\ Joseph Rodrigues ${ }^{1}$ \\ ${ }^{I}$ Department of Electrical and Electronics Engineering, School of Engineering and Technology, \\ CHRIST (Deemed to be University), Bangalore - 560074, Karnataka, India \\ * Corresponding author’s Email: nirmala.john@ christuniversity.in
}

\begin{abstract}
Due to numerous operational restrictions and economic purposes, optimal load management for energy balance in the smart grid (SG) is one of the compensating responsibilities. This research provides a novel multiobjective optimization technique for attaining energy balance in SG, with the goal of avoiding fines due to excessive upstream network power extraction beyond contractual demand. Due to a lack of capacity to create the whole optimization towards the global optimum after each run, optimal load control (OLC) is a prevalent challenge. Adaptive-TLBO, the most recent variation of Teaching Learning Based Optimization (TLBO), comprises both alterations during the exploitation and exploration phases (ATLBO). Because the ATLBO is used on a modified IEEE 33-bus system, the results obtained in this mode are extraordinary. The energy balance has improved in addition to the enhancement of the voltage profile and the reduction of distribution losses. As evidenced by comparisons with PSO, basic TLBO, backtracking search algorithm (BSA), and cuckoo search algorithms, the suggested ATLBO algorithm has precedence over any other proposed algorithm (CSA).
\end{abstract}

Keywords: Smart grid, Optimal load control, Adaptive teaching-learning-based optimization, Multi-objective optimization.

\section{Introduction}

Electricity is in high demand in today's power grid. This has led to an imbalance between supply and demand for power. Traditional methods have been adjusted to match the needs, but this wastes time and money. However, difficulties of distribution network performance and transmission system support remain. Achieving effective control over transmission line power flows using flexible AC transmission system (FACTS) devices, renewable energy (RE) sources, and other efficient power management devices on the distribution side has been a goal of modern transportation systems. Load shedding (LS) is also used as an emergency corrective step to provide appropriate stability margin and prevent voltage collapse/blackout. This will also return the electrical system to normal. A load shedding solution for energy balancing in MGs is defined as either under voltage load shedding (UVLS) or frequency load shedding (FLS) (UFLS). However, in these two categories, customer engagement and satisfaction are not included.

The microgrid (MG) [1] is capable of operating in either an islanding/stand-alone grid or a main gridintegrated mode, depending on the scenario. The second sort of generation is islanding, which involves assessing the MG's strength and redeploying power to various loads once it is disconnected from the main grid. All of the following utilities are the operator's duty and typically utility driven. The global power industry was restructured in 1988. Since then, multiple degrees of customer participation in the operation and management of the electrical system have been recognised. The electricity sector has been restructured globally since 1998 [2]. For example, even in the absence of authority, economic objectives with varying priorities may be achieved [3]. Insufficient power supply may lead to poor dependability and dissatisfaction among consumers. 
To address this problem, utilities worldwide have proposed demand response (DR) [4] and demand side management (DSM) [5] initiatives. Customer engagement is required to ensure programme dependability and security. This reduces peak demand. DR programmes may be characterised as incentive-based or time-based [5-7].

The time-based programmes are well-known and in use internationally. The consumer is allowed to move his load from one period to another based on the electrical market price signal. Second, incentivebased systems are designed to lower system demand during peak load periods or in unpredictable situations like as generator, line, or transformer failures. There are reduced elasticity tariffs or specific incentives depending on the market regulations. The information and communication technologies and control system (ICT \& CS) is the key for success of these systems. Also, customer engagement is still debated in many projects [8]. Determining $M G$ efficiency without sacrificing dependability, economics, or security becomes critical.

There was no such thing as a universal energy management system (EMS) for all MG topologies. Researchers are still working on developing alternative EMS for dispatchable and nondispatchable distribution (DG). These may include EVs, renewable energy, DR programmes, and energy storage systems (ESS) to achieve energy balance in MG operation. Various meta-heuristic algorithms have probably addressed the challenge of locating potential OLC sites, controlling load, and shedding load.

[9] proposes a weighted sum genetic algorithm to avoid voltage collapse under line contingencies. The positions are chosen using a multi-objective function, and the NVSI is designed to optimise voltage stability while reducing demand on the power system. The best load shed for balancing generation and demand at Selçuk university medical faculty is provided in [10]. With generating shortages, a hybrid solution employing evolutionary algorithms and artificial neural networks is proposed to reduce load shed and increase voltage stability [11]. Backtracking search algorithms (BSA) are preferable for islanded systems with variable distribution generation (DG) penetration [12]. The algorithm is submitted for multiple voltage stability indices. Load management is required for reliable operation under varying DG penetration, loss of generation or line contingency. In the DR scenario, proper load shed distribution and customer satisfaction are vital. Also, energy balancing is one of the acknowledged MG accomplishments. Many do not concentrate on reactive power (VAr) to decrease load control/maximize load dispatch. The paper focuses on optimum capacitor bank allocation and renewable energy-based DG allocation. This is used to improve MG performance in technical, economic, and financial terms [13]. [14] discusses supply and demand side optimal load scheduling strategies in SG. However, energy balancing with numerous objective functions, continuous and discrete choice variables, and equal and unequal restrictions. An efficient heuristic approach is required to solve non-linear complex optimization problems [15].

This work proposes an efficient social-inspired meta-heuristic algorithm teaching-learning-based optimization (TLBO) [16, 17] for establishing optimum load management for energy balance in MG to maximise social welfare. The fundamental TLBO has attracted many academics because to its efficient convergence properties [18]. In comparison to previous TLBO variations based on inertia weights, ATLBO has proven advantages [19]. ATLBO introduces three important changes. Initially, a chaotic beginning population is recommended to generate a varied class to avoid local optima. The second change is the addition of adaptive exponential distribution inertia weight to improve solution efficiency and convergence rate, thereby balancing the exploration and exploitation phases. The third change is the inertia-weight update.

Rest of the paper is structured as follows: An equal and unequal constraint multi-objective optimization problem is described mathematically in section. Section 3 presents the TLBO idea and its adaptations for ATLBO. Section 4 presents simulation results on IEEE 33-bus EDN, while Section 5 highlights important study findings.

\section{Problem formulation}

\subsection{Multi-objective function}

Any power system's main goal is to maintain energy balance. In grid-connected mode, MG's power consumption is considered to be restricted to contracted power. Such, the target function is to optimize the load control settings so that the total demand (load + losses) equals contractual power,

$$
\Delta P_{(t)}=\left\{k_{(t)} P_{D}^{m}-\left[\left(\sum_{i=1}^{n_{b}} \rho_{c(i)} P_{d(i)}^{m}\right)+P_{l}\right]\right\}
$$

where $P_{D}^{m}$ and $P_{d(i)}^{m}$ are the maximum demand of MG and connected demand at bus- $i$, respectively; $P_{l}$ is the total distribution losses, $k_{(t)}$ is a scaling factor used to define the amount contracted power by MG 
at hour-t, $\rho_{c(i)}$ is a scaling factor used to define the amount of load to be controlled at bus- $i, n_{b}$ is the number of buses in MG.

If MG extracts more power than contracted, the penalty can be imposed on the MG operator is calculated and it is given by,

$$
C_{P(t)}=\sum_{t=1}^{24} \Delta P_{(t)} \times \gamma_{(t)}
$$

where $C_{P(t)}$ is the total penalty in 24-hour optimization time horizon for extracted power $\Delta P_{(t)}$ more than contracted power $k_{(t)} P_{D}^{m}, \gamma_{(t)}$ is the price defined for penalty at hour- $t$. Here, the same penalty cost is treated as savings under less consumption than contracted power.

\subsection{Operational constraints}

The major equal constraints considered under this study are active and reactive power balances between hourly contracted power and load points. They are given by,

$$
\begin{aligned}
& \sum_{i=1}^{n_{b}} P_{d(i)}+P_{l}=\rho_{c(i)} P_{D}^{m} \\
& \sum_{i=1}^{n_{b}} Q_{d(i)}+Q_{l}=\rho_{c(i)} Q_{D}^{m}
\end{aligned}
$$

where $Q_{d(i)}$ is the reactive power demand at bus-i, $Q_{D}^{m}$ and $Q_{l}$ are the maximum reactive power demand and total reactive power loss in the MG, respectively.

Similarly, voltage magnitude limits at all buses $\left|V_{(i)}\right|$, current/thermal limit for all branches $I_{b(i)}$, and load control limit for all buses $\rho_{c(i)}$ are considered as unequal constraints under this study. Mathematically,

$$
\begin{aligned}
& \left|V_{(i)}^{\min }\right| \leq\left|V_{(i)}\right| \leq\left|V_{(i)}^{\min }\right| \\
& I_{b(i)} \leq I_{b(i)}^{\max } \\
& \rho_{(i)}^{\min } \leq \rho_{c(i)} \leq \rho_{(i)}^{\max }
\end{aligned}
$$

The major control variables that are treated as search variables in the optimization problem are active power balance by optimally tuning the consumers' load control factor. Instead of a uniform load control factor for all buses, determining appropriate/optimal load control factor for every buses makes this optimization problem more SGfriendly while also satisfying each consumer's desire to participate in the demand response (DR) programme.

\section{Teaching-learning-based optimization}

Teaching and learning are two interrelated, crucial, and constant activities in everyone's life. Rao et al. (2011) proposed an unique optimization approach called Teaching-Learning-Based Optimization (TLBO) for a single instructor in a typical classroom $[16,17]$. The TLBO algorithm divides students' learning into two types: teacher-led and peer-led. The teacher phase and the learner phase replicate the investigation and exploitation stages of the optimization process, respectively. The number of students and topics correspond to the population size and design factors. As with the optimization problem, the best student in the class is viewed as a teacher. The next part describes the instructor and student mathematical models. The TLBO algorithm allows advanced novices to study more efficiently by recognising their grades.

\subsection{Basic TLBO}

The number of students/ population are denoted as $n(k=1,2 \ldots n)$, and number of subjects/ design variables as $m(j=1,2 \ldots m)$. The position of the $i$ th student in a class can define by,

$$
X_{i, j}=\left\{X_{i, 1}, X_{i, 2}, \ldots, X_{i, m}\right\}
$$

Knowing lower $\left(L_{m}\right)$ and upper marks $\left(U_{m}\right)$ of class in each subject i.e., $X_{i, j} \in\left[L_{m}, U_{m}\right]$, the initial population can generate randomly and is given by,

$$
X_{i, j}=L_{m}+r_{1}\left[U_{m-} L_{m}\right]
$$

where $r_{1}$ is uniformly distributed random numbers. These process of improving the initial grades in TLBO by Teacher and Learner phases, are explained below.

\subsubsection{Teacher phase}

This step of the algorithm simulates all students studying from a teacher. This is comparable to conventional education, when the instructor discusses a subject's ideas to all pupils. He also works to raise the class's average test score. Also, a teacher or local best of that iteration models the class mean performance in a given topic as $M_{i, j}$ and the best learner among all pupils as $X_{i b, j}$. The quality of pupils and instructors, as well as $T_{f}$ is the teacher's effort, influence the learning stage. This phenomenon is quantified as the difference in mean performance $D M_{i, j}=\left(\sum X_{i, j}\right) / n$ between the local best and the whole class, as shown in Eq (10). 


$$
D M_{i, j}=r_{i}\left(X_{i b, i}-T_{f} M_{i, j}\right)
$$

Here, $T_{f}$ is the teaching factor describes the effort made by a teacher to reduce the difference in mean performance w.r.t. the best learner. Notably, $T_{f}$ is not an input parameter of the TLBO algorithm and is generated randomly with equal probability as defined in Eq. (11).

$$
T_{f}=\operatorname{round}\left[1+r_{2} \cdot(2-1)\right]
$$

where $r_{i}$ and $r_{j}$ are random numbers in the range of $[0,1]$. At the end of the teaching phase, all the learners are updated as expressed in Eq. (12), if the objective function results are better than the previous, they are carried forward to the next learner phase as input variables.

$$
X_{i, j(k)}^{\prime}=X_{i, j(k)}+D M_{i, j}
$$

At this stage, it can be said that the performance of TLBO depends on $T_{f}$ and $r_{2}$ stands unique. This is said in comparison to the other traditional heuristic algorithms where various input parameters are required for tuning and getting better performance.

\subsubsection{Learner phase}

This second phase of the algorithm simulates the learning mode of a learner by conducting active interaction or discussion with other learners. A more knowledgeable student can help a fellow student. The modeling of this phase is described as follows: Two students, A and B were randomly selected and their performances were recorded at the end of the teaching phase, such that $X_{i, j(A)}^{\prime}=X_{i, j(B)}^{\prime}$. The learners are updated and defined in Eq. (13) if $X_{i, j(A)}^{\prime}>X_{i, j(B)}^{\prime}$ and Eq. (14) if $X_{i, j(A)}^{\prime}<X_{i, j(B)}^{\prime}$, for the objective function results are better than the previous.

$$
\begin{aligned}
& X_{i, j(A)}^{\prime}=X_{i, j(A)}^{\prime}+r_{3}\left(X_{i, j(A)}^{\prime}-X_{i, j(B)}^{\prime}\right) \\
& X_{i, j(A)}^{\prime}=X_{i, j(A)}^{\prime}+r_{4}\left(X_{i, j(B)}^{\prime}-X_{i, j(A)}^{\prime}\right)
\end{aligned}
$$

Then the above equations hold true for maximization problems. It will also be sufficient to model them in reverse in case of minimization problems.

\subsection{Adaptive-TLBO (ATLBO) algorithm}

The key changes in this revised TLBO are: I random beginning population students may be added to this diverse class. This will lead to an algorithm that can escape local optima. ii) Inertia weight. iii) Position update via inertia-weight technique. These three changes to constructing a new ATLBO algorithm are described below. The computing efficiency of any heuristic method is dictated on the initial population generation. It's important in TLBO. The Logistic-map is a great chaotic sequence. It can map the current population value to the next time step, hence it is used to initialise a random population. Given by,

$$
x_{t+1}=r \cdot x_{t}\left(1-x_{t}\right)
$$

where $x_{t}$ the representation of the population/ chaotic variable at any given time $t$. It is constructed for a fixed continuous set of four periodic static points $(0$, $0.25,0.5,0.75$, and 1 ).

The adaptive exponential distribution inertia weight (AEDIW) is defined as follows,

$$
\begin{aligned}
& \omega=-\rho_{1} e^{-\delta \gamma}+\rho_{2} e^{\delta \gamma},\left(L_{m}<\delta<U_{m}\right) \\
& \rho_{1}=\omega_{2} e^{-\gamma}+\omega_{1} e^{\gamma} \\
& \rho_{2}=-\omega_{1} e^{2 \gamma}-\omega_{2}
\end{aligned}
$$

where $\omega_{1}, \omega_{2}$ and $\gamma$ are positive real numbers. Unlike in basic TLBO, when students are updated individually, here we update all students jointly, thus Eq. (19),

$$
X_{i, j(k)}^{\prime}=\omega X_{i, j(k)}+D M_{i, j}
$$

This new ATLBO variation has achieved amazing performance in terms of optimum mean and standard deviation by modifying the fundamental TLBO. The issue of benchmark functions repeating was also handled.

\section{Results and discussion}

EDNs are radial in nature. So the IEEE 33-bus radial distribution network (RDN) [20] was selected to test the suggested technique. All load sites are considered as controlled loads in line with DLC and DR programmes as possible in SG environment. A centralised EMS is also in the works. To achieve efficient operation, determine effective load management, and communicate and manage all financial settlements among all members.

The IEEE 33-bus network requires $(3715+2300)$ $\mathrm{kVA}$ total actual and reactive power. This MG's net effective demand on the main grid is $(3924.64 \mathrm{~kW}+$ j 2442.05 kVAr) sans DGs. It is regarded as the MG's 
peak demand (load plus losses). Total distribution losses are $(210.998+\mathrm{j} 143.033) \mathrm{kVA}$, with bus-18 having the lowest voltage of 0.9038 p.u.

\subsection{Network performance before load control}

In this case, only the main grid serves the whole MG demand (load and losses). The DGs are ignored here. All loads are constant power loads. Table 1 shows the load scaling factor $k_{(t)}$ as an hourly permissible main-grid load level vs. peak load. Reduce the load on each bus to the hourly authorised load level before OLC installation. The MG draws more than allowed, including losses, therefore the error is negative. The MG operator may be fined according to mutual agreement. The penalty charges are estimated to be $0.25 \$ / \mathrm{h}$ for (hour $1: 9$ ), $0.5 \$ / \mathrm{h}$ for (hour 10:17), and 0.75 $\$ / \mathrm{h}$ for (hour 18:24).

Using the given data, the MG drawn 4080.06 $\mathrm{kW} /$ day additional electricity owing to distribution losses, resulting in a daily penalty of $2008.93 \$$. So OLC's goal isn't to pull additional MG power at any time. It also avoids fines.

\subsection{Network performance after load control}

In this example, the MG is assumed to be gridconnected with no integrated DGs. Thus, the demand for MG is planned to be restricted to the allowable hourly load. To get the load control factor search space matrix $[0.5,1.0]$, multiply by DLC allows a maximum load reduction of $50 \%$ on any load bus. The population and search variables are 50 and equal to the number of buses in MG, respectively.

Table 2 shows ATLBO's ideal results. Positive error indicates a deviation from the permissible demand. It is computed as the permissible load $\left(3715 \times k_{(t)}\right)$ - electricity extracted from the main grid $(\mathrm{kW})$. Its precision while delivering appropriate load management relative to permissible demand.

Based on the findings shown in Table 2, the MG is using $26.83 \mathrm{~kW} /$ day more electricity than allowed, saving 10.55 \$ per day. Fig. 1 shows the grid power extracted before and after the OLC procedure. The permissible power and extracted power under the OLC scheme are practically identical, demonstrating ATLBO's precision in establishing load control variables. ATLBO's performance is compared to PSO, CSA, and simple TLBO. The allowable power demand factor is $0.85(3715.2 \mathrm{~kW})$. Table 3 shows the outcomes of several algorithms. The findings show that ATLBO outperforms all other algorithms in terms of accuracy. Figs. 2 and 3 show the resulting actual and reactive power needs.

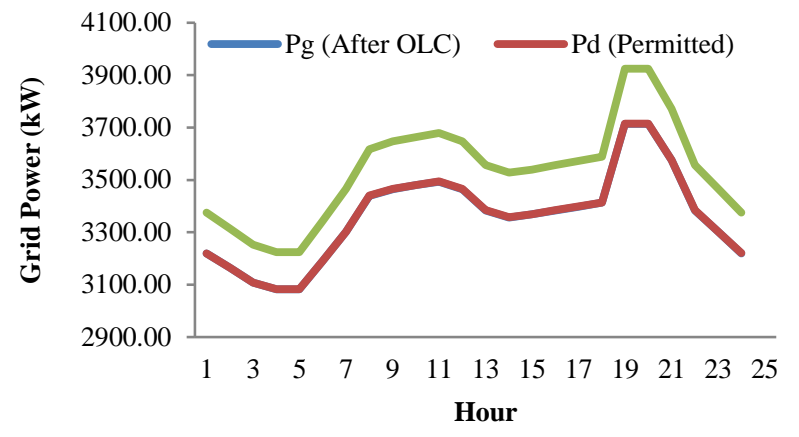

Fig. 1 Grid power drawn by MG before and after OLC by ATLBO

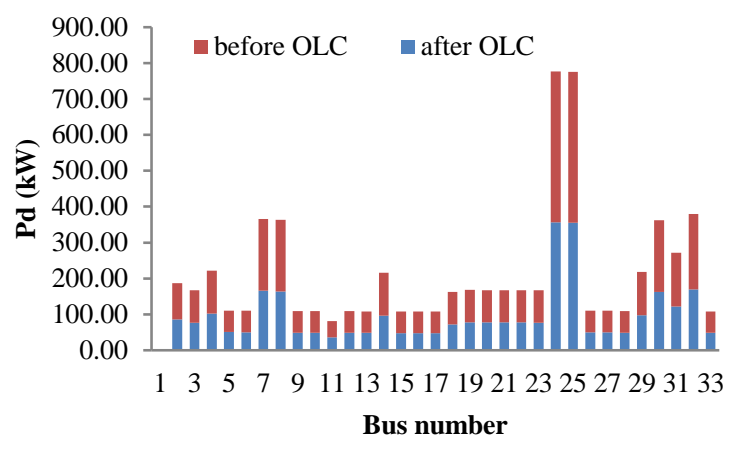

Fig. 2 Real power load before and after OLC by ATLBO

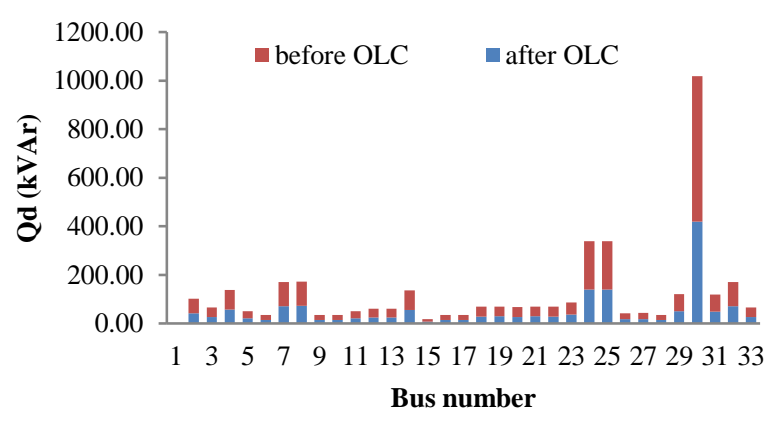

Fig. 3 Reactive power load before and after OLC by ATLBO

\subsection{Comparison of ATLBO with literature}

The performance of ATLBO is compared with (i) uniform load control factor for all buses, (ii) basic TLBO and (iii) backtracking search algorithm (BSA) [12]. Test system data including maximum load control change at bus is the same as in [12]. The peak hour-9 scenario from [12] is chosen for comparison.

2.575 MW hour-9 load (i.e., 69.314 percent of peak load of $3.715 \mathrm{MW}$ ). However, the total power available in the system is $1.414 \mathrm{MW}$, supplied by DG sources. This scenario calls for load control due to a 45.087 percent power production shortage.

TLBO and ATLBO are used to compare network performance to BSA [12]. In Case 1, a uniform 
Table 1. Network performance before implementing OLC

\begin{tabular}{|c|c|c|c|c|c|c|c|c|c|c|}
\hline $\mathrm{Hr}$ & $k_{(t)}$ & $\begin{array}{l}\mathbf{P}_{\mathbf{g r}} \\
(\mathrm{kW})\end{array}$ & $\begin{array}{l}\begin{array}{l}\mathrm{gr} \\
(\mathrm{kVAr})\end{array} \\
\end{array}$ & $\begin{array}{l}\begin{array}{l}P_{D} \\
(k W)\end{array} \\
\end{array}$ & $\begin{array}{l}\begin{array}{l}\text { QD } \\
\text { (kVAr) }\end{array} \\
\end{array}$ & $\begin{array}{l}\begin{array}{l}P_{\text {loss }} \\
(\mathrm{kW})\end{array} \\
\end{array}$ & $\begin{array}{l}\begin{array}{l}\text { Qloss } \\
\text { (kVAr) }\end{array} \\
\end{array}$ & $\begin{array}{l}V_{\min } \\
\text { @ } 18 \\
\end{array}$ & $\begin{array}{l}\Delta P \\
(\mathrm{~kW})\end{array}$ & $\begin{array}{l}\begin{array}{l}\text { Penalty } \\
(\$ / h)\end{array} \\
\end{array}$ \\
\hline 1 & 0.867 & 3376.09 & 2099.25 & 3220.91 & 1994.10 & 155.18 & 105.15 & 0.9176 & -155.18 & 38.62 \\
\hline 2 & 0.852 & 3314.68 & 2060.90 & 3165.18 & 1959.60 & 149.50 & 101.30 & 0.9191 & -149.50 & 37.21 \\
\hline 3 & 0.837 & 3253.39 & 2022.62 & 3109.46 & 1925.10 & 143.93 & 97.52 & 0.9207 & -143.93 & 35.83 \\
\hline 4 & 0.830 & 3224.83 & 2004.79 & 3083.45 & 1909.00 & 141.38 & 95.79 & 0.9214 & -141.38 & 35.20 \\
\hline 5 & 0.830 & 3224.83 & 2004.79 & 3083.45 & 1909.00 & 141.38 & 95.79 & 0.9214 & -141.38 & 35.20 \\
\hline 6 & 0.859 & 3343.33 & 2078.79 & 3191.19 & 1975.70 & 152.14 & 103.09 & 0.9184 & -152.14 & 37.86 \\
\hline 7 & 0.889 & 3466.38 & 2155.66 & 3302.64 & 2044.70 & 163.74 & 110.96 & 0.9153 & -163.74 & 40.73 \\
\hline 8 & 0.926 & 3618.81 & 2250.93 & 3440.09 & 2129.80 & 178.72 & 121.13 & 0.9115 & -178.72 & 44.44 \\
\hline 9 & 0.933 & 3647.74 & 2269.01 & 3466.10 & 2145.90 & 181.64 & 123.11 & 0.9108 & -181.64 & 45.16 \\
\hline 10 & 0.937 & 3664.29 & 2279.35 & 3480.96 & 2155.10 & 183.33 & 124.25 & 0.9104 & -183.33 & 91.16 \\
\hline 11 & 0.941 & 3680.84 & 2289.70 & 3495.82 & 2164.30 & 185.02 & 125.40 & 0.9100 & -185.02 & 91.99 \\
\hline 12 & 0.933 & 3647.74 & 2269.01 & 3466.10 & 2145.90 & 181.64 & 123.11 & 0.9108 & -181.64 & 90.33 \\
\hline 13 & 0.911 & 3556.93 & 2212.24 & 3384.37 & 2095.30 & 172.56 & 116.94 & 0.9131 & -172.56 & 85.83 \\
\hline 14 & 0.904 & 3528.08 & 2194.22 & 3358.36 & 2079.20 & 169.72 & 115.02 & 0.9138 & -169.72 & 84.43 \\
\hline 15 & 0.907 & 3540.44 & 2201.94 & 3369.51 & 2086.10 & 170.93 & 115.84 & 0.9135 & -170.93 & 85.03 \\
\hline 16 & 0.911 & 3556.93 & 2212.24 & 3384.37 & 2095.30 & 172.56 & 116.94 & 0.9131 & -172.56 & 85.83 \\
\hline 17 & 0.915 & 3573.42 & 2222.55 & 3399.23 & 2104.50 & 174.19 & 118.05 & 0.9127 & -174.19 & 86.64 \\
\hline 18 & 0.919 & 3589.92 & 2232.86 & 3414.09 & 2113.70 & 175.83 & 119.16 & 0.9122 & -175.83 & 131.18 \\
\hline 19 & 1.000 & 3926.00 & 2443.03 & 3715.00 & 2300.00 & 211.00 & 143.03 & 0.9038 & -211.00 & 157.23 \\
\hline 20 & 1.000 & 3926.00 & 2443.03 & 3715.00 & 2300.00 & 211.00 & 143.03 & 0.9038 & -211.00 & 157.23 \\
\hline 21 & 0.963 & 3772.02 & 2346.72 & 3577.55 & 2214.90 & 194.47 & 131.82 & 0.9077 & -194.47 & 145.00 \\
\hline 22 & 0.911 & 3556.93 & 2212.24 & 3384.37 & 2095.30 & 172.56 & 116.94 & 0.9131 & -172.56 & 128.75 \\
\hline 23 & 0.889 & 3466.38 & 2155.66 & 3302.64 & 2044.70 & 163.74 & 110.96 & 0.9153 & -163.74 & 122.20 \\
\hline 24 & 0.867 & 3376.09 & 2099.25 & 3220.91 & 1994.10 & 155.18 & 105.15 & 0.9176 & -155.18 & 115.85 \\
\hline
\end{tabular}

Table 2. Network performance after implementing OLC using ATLBO

\begin{tabular}{lllllllllll}
\hline \hline $\mathbf{H r}$ & $\boldsymbol{\kappa}$ & $\begin{array}{l}\mathbf{P}_{\mathbf{g r}} \\
(\mathbf{k W})\end{array}$ & $\begin{array}{l}\mathbf{Q}_{\mathbf{g r}} \\
(\mathbf{k V A r})\end{array}$ & $\begin{array}{l}\mathbf{P} \mathbf{k} \\
(\mathbf{k W})\end{array}$ & $\begin{array}{l}\text { Qd } \\
(\mathbf{k V A r})\end{array}$ & $\begin{array}{l}\mathbf{P}_{\text {loss }} \\
(\mathbf{k W})\end{array}$ & $\begin{array}{l}\mathbf{Q}_{\text {loss }} \\
(\mathbf{k V A r})\end{array}$ & $\begin{array}{l}\mathbf{V}_{\min } \\
@ \mathbf{1 8}\end{array}$ & $\begin{array}{l}\Delta P \\
(\mathbf{k W})\end{array}$ & $\begin{array}{l}\text { Savings } \\
(\mathbf{\$} / \mathbf{h})\end{array}$ \\
\hline 1 & 0.867 & 3219.23 & 1997.61 & 3078.63 & 1902.30 & 141.19 & 95.74 & 0.9213 & 1.68 & 0.217 \\
2 & 0.852 & 3164.57 & 1966.29 & 3028.86 & 1874.31 & 136.26 & 92.38 & 0.9227 & 0.61 & 0.213 \\
3 & 0.837 & 3107.21 & 1899.87 & 2979.72 & 1813.50 & 127.97 & 86.72 & 0.9252 & 2.24 & 0.209 \\
4 & 0.830 & 3082.36 & 1876.69 & 2957.34 & 1792.18 & 125.48 & 84.83 & 0.9262 & 1.09 & 0.208 \\
5 & 0.830 & 3082.36 & 1876.69 & 2957.34 & 1792.18 & 125.48 & 84.83 & 0.9262 & 1.09 & 0.208 \\
6 & 0.859 & 3190.59 & 1980.74 & 3052.89 & 1887.44 & 138.26 & 93.71 & 0.9221 & 0.59 & 0.215 \\
7 & 0.889 & 3301.93 & 2060.78 & 3152.90 & 1959.83 & 149.70 & 101.44 & 0.9197 & 0.71 & 0.222 \\
8 & 0.926 & 3439.35 & 2103.02 & 3282.05 & 1996.40 & 158.03 & 107.16 & 0.9159 & 0.74 & 0.232 \\
9 & 0.933 & 3465.14 & 2151.74 & 3301.55 & 2041.00 & 164.39 & 111.33 & 0.9154 & 0.96 & 0.233 \\
10 & 0.937 & 3480.02 & 2189.86 & 3312.93 & 2076.59 & 167.93 & 113.89 & 0.915 & 0.94 & 0.469 \\
11 & 0.941 & 3493.66 & 2196.66 & 3327.75 & 2084.22 & 166.75 & 113.05 & 0.9148 & 2.15 & 0.471 \\
12 & 0.933 & 3464.93 & 2166.83 & 3304.93 & 2058.89 & 160.76 & 108.49 & 0.9182 & 1.17 & 0.467 \\
13 & 0.911 & 3383.58 & 2075.20 & 3231.02 & 1971.60 & 153.26 & 104.11 & 0.9176 & 0.79 & 0.456 \\
14 & 0.904 & 3356.76 & 2149.48 & 3193.39 & 2038.46 & 164.22 & 111.64 & 0.9153 & 1.60 & 0.452 \\
15 & 0.907 & 3368.91 & 2014.57 & 3225.64 & 1917.80 & 143.86 & 97.20 & 0.9211 & 0.60 & 0.454 \\
16 & 0.911 & 3383.39 & 2114.21 & 3223.75 & 2006.17 & 160.42 & 108.61 & 0.9181 & 0.98 & 0.456 \\
17 & 0.915 & 3398.30 & 2155.65 & 3235.60 & 2044.99 & 163.53 & 111.27 & 0.9139 & 0.92 & 0.458 \\
18 & 0.919 & 3413.17 & 2166.09 & 3255.46 & 2059.56 & 158.44 & 107.06 & 0.9188 & 0.91 & 0.689 \\
19 & 1.000 & 3713.88 & 2297.44 & 3527.03 & 2170.73 & 187.92 & 127.48 & 0.9091 & 1.12 & 0.750
\end{tabular}




\begin{tabular}{lllllllllll}
20 & 1.000 & 3713.88 & 2297.44 & 3527.03 & 2170.73 & 187.92 & 127.48 & 0.9091 & 1.12 & 0.750 \\
21 & 0.963 & 3575.60 & 2186.35 & 3406.80 & 2072.18 & 169.64 & 114.79 & 0.9147 & 1.95 & 0.722 \\
22 & 0.911 & 3383.58 & 2074.50 & 3229.03 & 1969.58 & 155.27 & 105.44 & 0.9165 & 0.79 & 0.683 \\
23 & 0.889 & 3301.84 & 2023.22 & 3153.51 & 1922.25 & 149.01 & 101.47 & 0.917 & 0.80 & 0.667 \\
24 & 0.867 & 3219.60 & 1970.99 & 3079.03 & 1875.41 & 141.18 & 96.03 & 0.9187 & 1.31 & 0.650 \\
\hline
\end{tabular}

Table 3. Comparison of ATLBO performance with other algorithms for LSF $=0.85$

\begin{tabular}{lllllllll}
\hline \hline \multirow{2}{*}{ Algorithm } & $\begin{array}{l}\text { Pg } \\
(\mathbf{k W})\end{array}$ & $\begin{array}{l}\text { Qg } \\
(\mathbf{k V A r})\end{array}$ & $\begin{array}{l}\text { Pd } \\
(\mathbf{k W})\end{array}$ & $\begin{array}{l}\text { Qg } \\
(\mathbf{k V A r})\end{array}$ & $\begin{array}{l}\text { Ploss } \\
(\mathbf{k W})\end{array}$ & $\begin{array}{l}\text { Qloss } \\
(\mathbf{k V A r})\end{array}$ & $\begin{array}{l}\text { Vmin } \\
\text { @ 18 }\end{array}$ & $\begin{array}{l}\Delta P \\
(\mathbf{k W})\end{array}$ \\
\hline Before OLC & 3306.5 & 2055.79 & 3157.75 & 1955 & 148.75 & 100.79 & 0.9193 & -148.75 \\
PSO & 3157.15 & 1931.44 & 3024.77 & 1841.82 & 132.38 & 89.62 & 0.9239 & 0.60 \\
CSA & 3157.51 & 1978.1 & 3019.94 & 1884.92 & 137.57 & 93.18 & 0.9227 & 0.24 \\
TLBO & 3157.54 & 1977.05 & 3020.67 & 1884.35 & 136.87 & 92.7 & 0.9228 & 0.21 \\
ATLBO & 3157.59 & 1957.54 & 3021.91 & 1865.54 & 135.68 & 92 & 0.9226 & 0.16 \\
\hline
\end{tabular}

Table 4. Comparison of ATLBO with BSA [12]

\begin{tabular}{llllllll}
\hline \hline Case \# & Algorithm & $\begin{array}{l}\mathrm{P}_{\text {load }} \\
(\mathrm{kW})\end{array}$ & $\begin{array}{l}\mathrm{Q}_{\text {load }} \\
(\mathrm{kVAr})\end{array}$ & $\begin{array}{l}\mathrm{P}_{\text {loss }} \\
(\mathrm{kW})\end{array}$ & $\begin{array}{l}\mathrm{Q}_{\text {loss }} \\
(\mathrm{kVAr})\end{array}$ & $\begin{array}{l}\mathrm{V}_{\text {min }} \\
(\mathrm{p} . \mathrm{u} .)\end{array}$ & $\begin{array}{l}\text { Load } \\
\text { Reduction } \\
(\%)\end{array}$ \\
\hline 1 & USF & 1407.61 & 871.47 & 6.202 & 5.165 & $0.988(18)$ & 62.11 \\
\hline \multirow{2}{*}{2} & TLBO & 1407.73 & 850.44 & 6.026 & 5.185 & $0.988(18)$ & 44.34 \\
& ATLBO & 1407.82 & 886.35 & 6.001 & 5.001 & $0.989(18)$ & 43.71 \\
& BSA [12] & $1.414^{*}$ & - & - & - & - & 46 \\
\hline
\end{tabular}

scaling factor (USF) across all load locations decreases MG demand to 1.414 MW. Total distribution losses of $6.2021 \mathrm{~kW}$ reduce entire output to $1.414 \mathrm{MW}$ and total load delivered to $1.408 \mathrm{MW}$. The comparative results are summarized in Table 4.

\section{Conclusion}

Due to many operational and economic restrictions, efficient load management is one of the smart grid's compensating duties. This paper proposes a novel multi-objective optimization technique for attaining energy balance in SG and avoiding contractual upstream network power extraction fines. OLC is a typical issue owing to a lack of capacity to calculate the global optimum after each run. Adaptive-TLBO involves adjustments in both the exploitation and exploration phases (ATLBO). The ATLBO is used on a modified IEEE 33-bus system, hence the results are extraordinary. The energy balance has improved as well as the voltage profile and distribution losses. The proposed ATLBO algorithm results for only $43.71 \%$ load reduction and beats NR LF (62.11 percent load reduction), basic TLBO (44.34 percent load reduction), and backtracking search algorithm (BSA) (with only 46 percent load reduction).

On the way to sustainability, most MGs now include renewable energy-based distribution generating and electric vehicles. In the absence of an energy storage system, their unpredictability is a key problem. However, islanding activities cannot be ignored. In such instance, good load management can efficiently balance the load with local available generation. These aspects are considered as future scope of this work.

\section{Conflicts of interest}

The authors declare no conflict of interest.

\section{Author contributions}

The authors confirm contribution to the paper as follows: First Author, Nirmala John: Conceptualization, Data collection, Methodology, Analysis and interpretation of results, Original Draft Preparation, Editing; Second author Varaprasad Janamala: Supervison, Validation, Investigation, Final review and approval of manuscript; Third Author, Joseph Rodrigues: Supervision, Final Review and approval of manuscript.

\section{Acknowledgments}

The authors wish to thank the management of Christ (Deemed to be University), Bangalore, India, for extending MATLAB software facilities and online library facilities for the successful execution and completion of the study. 


\section{References}

[1] M. S. Mahmoud, S. A. Hussain, and M. A. Abido, "Modeling and control of microgrid: An overview", Journal of the Franklin Institute, Vol. 351, No. 5, pp. 2822-2859, 2014.

[2] M. M. Tripathi, A. K. Pandey, and D. Chandra, "Power system restructuring models in the Indian context", The Electricity Journal, Vol. 29, No. 4, pp. 22-27, 2016.

[3] A. Salgotra and S. Verma, "Power sector reforms and energy efficiency initiatives: The Indian experience", Energy Sources, Part B: Economics, Planning, and Policy, Vol. 11, No. 9, pp. 849-854, 2016.

[4] A. F. Meyabadi and M. H. Deihimi, "A review of demand-side management: Reconsidering theoretical framework", Renewable and Sustainable Energy Reviews, Vol. 80, pp. 367379, 2017.

[5] P. Siano, "Demand response and smart grids-A survey", Renewable and Sustainable Energy Reviews, Vol. 30, pp. 461-478, 2014.

[6] L. Gelazanskas and K. A. Gamage, "Demand side management in smart grid: A review and proposals for future direction", Sustainable Cities and Society, Vol. 11, pp. 22-30, 2014.

[7] N. G. Paterakis, O. Erdinç, and J. P. Catalão, "An overview of Demand Response: Keyelements and international experience", Renewable and Sustainable Energy Reviews, Vol. 69, pp. 871-891, 2017.

[8] N. Good, K. A. Ellis, and P. Mancarella, "Review and classification of barriers and enablers of demand response in the smart grid", Renewable and Sustainable Energy Reviews, Vol. 72, pp. 57-72, 2017.

[9] R. Kanimozhi, K. Selvi, and K. M. Balaji, "Multi-objective approach for load shedding based on voltage stability index consideration", Alexandria Engineering Journal, Vol. 53, No. 4, pp. 817-825, 2014.

[10] H. Çimen and M. Aydın, "Optimal load shedding strategy for Selçuk university power system with distributed generation", ProcediaSocial and Behavioral Sciences, Vol. 195, pp. 2376-2381, 2015.

[11] V. Tamilselvan and T. Jayabarathi, "A hybrid method for optimal load shedding and improving voltage stability", Ain Shams Engineering Journal, Vol. 7, No. 1, pp. 223-232, 2016.

[12] A. Khamis, H. Shareef, A. Mohamed, and Z. Y. Dong, "A load shedding scheme for DG integrated islanded power system utilizing backtracking search algorithm", Ain Shams Engineering Journal, Vol. 9, No. 1, pp. 161-172, 2018.

[13] S. Kalambe and G. Agnihotri, "Loss minimization techniques used in distribution network: bibliographical survey", Renewable and Sustainable Energy Reviews, Vol. 29, pp. 184-200, 2014.

[14] X. Lu, K. Zhou, X. Zhang, and S. Yang, “A systematic review of supply and demand side optimal load scheduling in a smart grid environment", Journal of Cleaner Production, Vol. 203, pp. 757-768, 2018.

[15] S. K. Rathor and D. Saxena, "Energy management system for smart grid: An overview and key issues", International Journal of Energy Research, Vol. 44, No. 6, pp. 4067-4109, 2020.

[16] R. V. Rao, V. J. Savsani, and D. P. Vakharia, "Teaching-learning-based optimization: a novel method for constrained mechanical design optimization problems", Computer-Aided Design, Vol. 43, No. 3, pp. 303-315, 2011.

[17] R. V. Rao, V. J. Savsani, and D. P. Vakharia, "Teaching-learning-based optimization: an optimization method for continuous non-linear large scale problems", Information Sciences, Vol. 183, No. 1, pp. 1-15, 2012.

[18] F. Zou, D. Chen, and Q. Xu, "A survey of teaching-learning-based optimization", Neurocomputing, Vol. 335, pp. 366-383, 2019.

[19] A. K. Shukla, P. Singh, and M. Vardhan, "An adaptive inertia weight teaching-learning-based optimization algorithm and its applications", Applied Mathematical Modelling, Vol. 77, pp. 309-326, 2020.

[20] O. Badran, J. Jallad, H. Mokhlis, and S. Mekhilef, "Optimal reconfiguration of distribution system connected with distributed generations: A review of different methodologies", Australian Journal of Electrical and Electronics Engineering, Vol. 17, No. 3, pp. 157-172, 2020. 